NBSIR 86-3396

\title{
NDE Publications: 1983
}

Leonard Mordfin, Editor

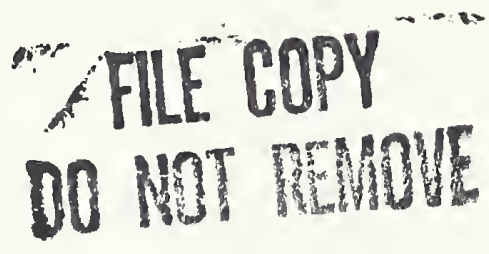

U.S. DEPARTMENT OF COMMERCE

National Bureau of Standards

Institute for Materials Science and Engineering

Office of Nondestructive Evaluation

Gaithersburg, MD 20899

April 1986

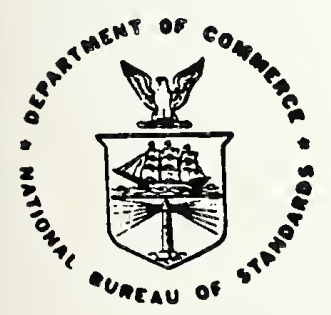

U.S. DEPARTMENT OF COMMERCE

NATIONAL BUREAU OF STANDARDS 

NBSIR 86-3396

NDE PUBLICATIONS: 1983

Leonard Mordfin, Editor

U.S. DEPARTMENT OF COMMERCE

National Bureau of Standards

Institute for Materials Science and Engineering

Office of. Nondestructive Evaluation

Gaithersburg, MD 20899

April 1986

U.S. DEPARTMENT OF COMMERCE, Malcolm Baldrige, Secretary NATIONAL BUREAU OF STANDARDS. Ernest Ambler, Director 

$\underline{\text { Page }}$

1. Introduction ................... 1

2. Bibliography and Abstracts ............ 3

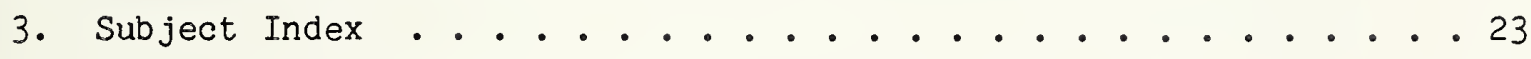

4. How to Obtain Copies................. 27 
NDE PUBLICATIONS: 1983

\author{
Leonard Mordfin \\ Office of Nondestructive Evaluation \\ Institute for Materials Science and Engineering \\ National Bureau of Standards \\ Gai thersburg, MD 20899
}

1. Introduction

This is the seventh in a series of bibliographies of NBS publications on nondestructive evaluation (NDE). Previous reports in this series have been :

NBSIR 78-1557, "NDE Publications: 1972-1977",
NBSIR 80-2080, "NDE Publications: 1978",
NBSIR 81-2351, "NDE Publications: 1979",
NBSIR 81-2364, "NDE Publications: 1980",
NBSIR 83-2741, "NDE Publications: 1981", and
NBSIR 85-3183, "NDE Publications: 1982".

This report provides bibliographic citations for publications that appeared in the open literature during the calendar year 1983. Also included are citations for several publications that appeared in previous years but were not listed in the earlier compilations.

Almost all of these publications were authored by members of the NBS staff and include papers published in non-NBS media as well as papers and reports from the NBS publications series. A few were written for NBS by non-NBS authors. Many of the publications cited are based on research that was supported, in whole or in part, by the NBS Office of Nondestructive Evaluation.

These publications address a wide variety of NDE methods, both those that are well established in industry and some that are relatively new. For completeness, several publications dealing with technologies that are closely related to modern NDE, such as process monitoring and nondestructive materials characterization have been included.

The format of this report is the same as that used previously. Brief, edited abstracts are provided for most of the publications cited. The bibliography and the abstracts comprise Section 2 of the report. The 104 entries of the bibliography are listed in alphabetical order by the surname of the first author. 
Section 3 of the report is a subject index for the publications listed. This index is quite comprehensive and, when used together with the abstracts and the alphabetical bibliography, may be expected to enable readers to locate publications of interest without difficulty.

The last section of the report provides some assistance to readers wishing to obtain copies of specific publications listed. 


\section{Bibliography and Abstracts}

1. Albus, J. S. Industrial robot technology and productivity improvement, Exploratory Workshop on the Social Impacts of Robotics: Summary and Issues, 62-89 (Feb. 1982). For sale by Superintendent of Documents.

Sensors are identified as one of the principal technical problem areas in industrial robotics. A brief survey of current work in this and other areas is given. Prospects for productivity improvement resulting from robotics in manufacturing are outlined.

2. Albus, J. S.; McLean, C. R.; Barbera, A. J.; Fitzgerald, M. L. Hierarchical control for robots in an automated factory, Proc. 13th Intl. Symp. on Industrial Robots and Robots 7, Vol. 2: Future Directions, pp. 13.29.-13.43 (Soc. Manufacturing Engineers, Dearborn, MI, 1983).

A hierarchical architecture for real-time sensory-interactive control of robots, machine tools, inspection machines, and materials transport and inventory systems is described. Feedback from sensors and from the control hierarchy itself are used at all levels to produce real-time goal-seeking behavior. A priori knowledge and sensor data are combined in a world model which is used to generate expectations and to plan alternate strategies at every level.

3. Alperin, H. A.; Singhal, S. P. Investigation of SiC-Al composite materials by neutron scattering, NBS Reactor: Summary of Activities July 1981 through June 1982, NBS Technical Note 1178, 123-125 (June 1983).

Upon application of increasing compressive stress to a cylindrical sample while it is undergoing neutron scattering measurements, it is possible to accurately measure the change in d-spacing as a function of applied stress independently for both the matrix and the fibers.

4. Anon. Program and abstracts, eighth international symposium on ultrasonic imaging and tissue characterization, June 5-8, 1983, Washington, DC, Ultrasonic Imaging 5, No. 2, 161-194 (April 1983).

5. Behrens, J. W.; Johnson, R. G.; Schrack, R. A. Neutron transmission measurements to determine isotopic content of spent fuel, Proc. Trans. Am. Nucl. Soc. 44, 204-205 (1983).

6. Berger, H.; Mordfin, L. Comparison of common nondestructive evaluation methods, Quality Progress 16, No. 2, p. 17 (Feb. 1983).

7. Birnbaum, G.; Berger, H.; Eitzen, D. G. Traceable NDE standards, CSNDT Journal 4, No. 4, 47-49 (Canadian Soc. NDT, Hamilton, Ont., Jan. 1983).

Recent work at NBS which has led to NDE standards and calibrations, as well as work in progress, is reviewed. 
8. Birnbaum, G.; Eitzen, D. G. Future directions of ultrasonic NDE standards in the U.S., Proc. 10th World Conf. on NDT, Moscow, USSR, Aug. 23-28, 1982, 267-272 (1982).

9. Birnbaum, G.; Vest, C. M. Holographic nondestructive evaluation: Status and future, Int. Adv. Nondestruct. Test 9, 257-282 (1983).

The status of the technique is reviewed, recent and potential technical advances are enumerated, and suggestions of activities which would enable full realization and evaluation of the potential of holographic NDE in the future are made.

10. Blau, P. J. Monitoring the sliding contact conditions in laboratory wear tests of metals using time-dependent variations in friction coefficients, Time-Dependent Failure Mechanisms and Assessment Methodologies (Proc. 35th Meeting of Mechanical Failures Prevention Group), J. G. Early, T. R. Shives, J. H. Smith, eds., 145-154 (Cambridge University Press, 1983).

The concept of monitoring sliding conditions by observing changes in friction coefficient may lead to improved reproducibility in laboratory testing as well as to a better knowledge of basic sliding processes. Several examples of friction coefficient variation analysis for dry sliding of metals will be given. The implications of this work to the understanding of how friction and wear may be related also will be discussed. More accurate understanding of this relationship can eventually lead to improved condition monitoring for many types of tribological systems.

11. Blau, P. J. Comparison of four microindentation hardness test methods using copper, 52100-steel, and an amorphous $\mathrm{Pd}-\mathrm{Cu}-\mathrm{Si}$ alloy, Metallography 16, No. 1, 1-18 (1983).

Microhardness numbers can be greatly affected by the nature of indenter/test piece interactions. The values obtained by traditional methods of microhardness calculations, using optical measurement of impression dimensions, can be misleading unless these interactions are taken into account. The effects of microstructure on microhardness numbers at various loads are explored.

12. Blessing, G. V. An assessment of ultrasonic reference block calibration methodology. NBSIR 83-2710, 23 p. (June 1983). Available from NTIS as PB $83-225870$.

The state-of-the-art in aluminum ultrasonic reference block calibration practices is reviewed, especially as it has been guided by the recommended practices of ASTM for aluminum blocks. The principal system variables in the calibration procedures are identified, and recommendations for reducing their associated measurement errors are made.

13. Blessing, G. V.; Bagley, P. P.; James, J. E. The effect of surface roughness on ultrasonic echo amplitude in steel, Proc. 1983 Ultrasonics Symposium, 923-927 (IEEE, Piscataway, NJ, 1983). 
The effects of several competing factors on echo amplitude were observed: scattering at the front (rough) surface, diffraction within the sample, and material attenuation. For a given roughness value, diffraction effects dominated at the lower frequencies, while scattering and attenuation dominated at the higher frequencies.

14. Bowman, C. D.; Schrack, R. A.; Behrens, J. W.; Johnson, R. G. Neutron resonance transmission analysis of reactor spent fuel assemblies, Neutron Radiography (Proc. 1st World Conf. on Neutron Radiography), 503-511 (Reidel, Dordrecht, Netherlands, 1983).

A method called Neutron Resonance Transmission Analys is is under study which would use a pulsed neutron beam for nondestructive isotopic assay of a complete spent fuel assembly. Neutrons removed from the collimated beam by absorption or scattering in the resonances of the various isotopes in the spent fuel appear as dips in the neutron transmission. The method is completely insensitive to matrix materials such as oxide, fuel cladding, and other structural members. The method offers high speed and modest operational cost, and it can be implemented with commercially available medical or radiographic gamma-ray generators adapted for neutron production.

15. Breckenridge, F. R.; Watanabe, T.; Hatano, H. Calibration of acoustic emission transducers: comparison of two methods, Proc. 6th Intl. Acoustic Emission Symp., 448-458 (Japanese Soc. for Non-Destructive Inspection, Tokyo, Japan, 1982).

An endeavor to compare two types of calibration of acoustic emission transducers was undertaken jointly by the Nippon Steel Corporation in Japan and NBS. In general, the absolute sensitivities of the transducers as obtained by the methods agree remarkably well.

16. Brown, D. W.; Lowry, R. E.; Smith, L. E. Prediction of the long term stability of polyester-based recording media. NBSIR 83-2750, 27 p. (June 1983). Available from NTIS as PB 83-261891.

The stability of poly(ethylene terephthalate) is being studied in order to predict its long term behavior as the base for film and magnetic tape. This report contains results of the second year's work. Film base, photographic film, and electrographic film are being aged at several temperatures and relative humidities. Acid contents, mechanical properties, and molecular weight have been measured at intervals. Magnetic tapes are also being aged, primarily to study the binder that holds the magnetic oxide to the substrate.

17. Burke, R. W.; Mavrodineanu, R. Standard reference materials: accuracy in analytical spectrophotometry. NBS Spec. Publ. 260-81, 140 p. (April 1983). SN003-003-02484-8.

The first part of this work presents a summary of the Standard Reference Materials (SRMs) that have been developed for checking the proper functioning of ultraviolet and visible spectrophotometers and includes a description of the high-accuracy spectrophotometer specially constructed for performing all of the transmittance measurements. The second part of this publication is devoted to a critical 
discussion of the analytical factors that can affect the accuracy of selected spectrophotometric procedures that have been widely used at NBS in the characterization of various SRMs.

18. Chang, Y. L.; Grot, R. A. Comparative analysis of thermographic inspections performed on retrofitted homes. NBSIR 83-2701, $191 \mathrm{p}$. (May 1983). Available from NTIS as PB 84-142231.

19. Cheng, Y. T.; Garrett, D. A. Resonance neutron radiography, Neutron Radiography (Proc. 1st World Conf. on Neutron Radiography), 513-517 (Reidel, Dordrecht, Netherlands, 1983).

A resonance neutron tomography project was carried out which included (1) construction of the reactor-based resonance neutron safeguards experimental system and provisions for its use, and (2) initial tomographic construction of a nuclear waste container.

20. Cheng, Y. T.; Schröder, I.; Ganoczy, M.; Carter, R. S. The neutron activation autoradiographic study of paintings, NBS Reactor: Summary of Activities July 1981 through June 1982, NBS Technical Note 1178, 188-195 (June 1983).

The neutron-activation autoradiography project sponsored by the Smithsonian Institution was progressing in two fronts during the past year. The first is the finalization of design concepts from scientists and art conservators. The second is the utilization of the present reactor thermal column for actual painting studies and the preparation of project supporting facilities.

21. Clough, R. B., ed. Quantitative NDE in the Nuclear Industry (Proc. 5 th Intl. Conf. on Nondestructive Evaluation in the Nuclear Industry) 471 p. (ASM, Metals Park, OH, 1983).

The conference first covered three main problem areas: the reactor pressure vessel, the primary pressure piping, and the steam generator. In addition, fuel materials problems were discussed in parallel sessions. Sessions were then devoted to NDE categorized by method: principally radiography, acoustic emission, ultrasonics, new techniques, as well as leak testing of valves. Eddy current methods were discussed in detail in the steam generator session. In addition codes and standards were discussed and an update was provided on the latest trends in advanced NDE applications programs.

22. Clough, R. B.; Wadley, H. N. G.; Mehrabian, R. Experimental studies of the dynamics of rapid solidification using acoustic emission, Rapid Solidification Processing Principles and Technologies, III (Proc. 3rd Conf. on Rapid Solidification Processing, Gaithersburg, MD, Dec. 1982), R. Mehrabian, ed., 403-415 (undated).

In this paper we discuss the use of acoustic emission methods to monitor rapid solidification of precisely controlled electron beam surface melts of commercially pure aluminum and 2219 aluminum alloy. The driving forces for the emission are the density changes due to phase transformations and the stresses induced by thermal contraction during and after solidification. 
23. Cohen, J. Elements of thermography for nondestructive testing. NBS Technical Note 1177, 35 p. (May 1983). SN003-003-02491-1.

This paper presents an elementary review of thermal imaging systems, with emphasis on the application of thermography to nondestructive testing. Topics discussed include heat radiation theory; early and contemporary thermal imaging systems; performance characteristics; effects of emissivity, background, temperature, atmospheres, and field of view.

24. Duga, J. J.; Fisher, W. H.; Buxbaum, R. W.; Rosenfield, A. R.; Buhr, A. R.; Honton, E. J.; McMillan, S. C. The economic effect of fracture in the United States. Part 2--A report to NBS by Battelle Columbus Laboratories. NBS Spec. Publ. 647-2, 352 p. (March 1983). SN003-003-02470-8.

A study was conducted to determine the cost of materials fracture in the U.S. economy and to identify means of reducing the cost.

Fracture costs were determined for all materials, all sectors of the economy, and all fracture modes. The costs were associated with both the occurrence of fracture and the prevention of fracture. See, also, item No. 76 .

25. Eckerle, K. L.; Weidner, V. R.; Hsia, J. J.; Chao, Z. W. Extension of a reference spectrophotometer into the near infrared. NBS Technical Note 1175,34 p. (April 1983). SN003-003-02477-5.

26. Eckerle, K. L.; Weidner, V. R.; Hsia, J. J.; Kafadar, K. Measurement assurance program transmittance standards for spectrophotometric linearity testing: preparation and calibration, J. Research NBS 88, No. 1, 25-36 (Jan.-Feb. 1983).

A Measurement Assurance Program for spectrophotometry is being established in order to assist laboratories involved in spectrophotometric calibrations. This paper deals with the preparation and calibration of neutral density glass filters for checking the linearity of photometric response, as applied to spectral transmittance measurements. Several sets of filters were prepared from suitable neutral glass. These filter sets will be available in three sizes. The filters were calibrated for spectral transmittance on the NBS Reference Spectrophotometer for high accuracy transmittance measurements.

27. Eitzen, D. G. Electric Power Research Institute/National Bureau of Standards joint program on acoustic emission, Nondestructive Evaluation Program: Progress in 1982, Report EPRI NP-2728-SR, Section 40, 16 p. (Electric Power Research Institute, Palo Alto, CA, Feb. 1983).

In this report we summarize some of our recent work towards quantitative acoustic emission measurements with the EPRI/NBS AE Program. The acoustic emission work which we describe here focuses on three areas: calibration and sensor activities, characterization of $\mathrm{AE}$ sources, and determination of source significance. Significant progress towards implementing a quantitative acoustic emission measurement system for continuously monitoring structures has been made. 
28. Eitzen, D.; Breckenridge, F.; Clough, R.; Hsu, N.; Proctor, T.; Simmons, J.; Stockton, C.; Wadley, H. N. G. Fundamental developments in acoustic emission measurements: the NBS program, Quantitative NDE in the Nuclear Industry (Proc. 5th Intl. Conf. on NDE in the Nuclear Industry), 315-325 (ASM, Metals Park, OH, 1983).

Recent NBS progress in the development of standards and improved measurement methods for quantitative acoustic emission measurements are reviewed. Results on generalizing the NBS AE transducer calibration service and on its relation to other methods are presented. Recent improvements in the design of a new piezoelectric AE transducer are presented. The new transducer measures normal surface displacement nearly as faithfully as the NBS standard capacitive transducer but with much greater sensitivity. It holds promise for use as a secondary calibration device and for application relying on causal signal processing. An indentation method for generating $\mathrm{AE}$ has been used to produce repeatable signals in temper and hydrogenembrittled steel. A multichannel $\mathrm{AE}$ system for characterizing $\mathrm{AE}$ events in steel has been tested with a laser thermoelastic source.

29. Fortunko, C. M.; Schramm, R. E. Analysis of electromagnetic-acoustic transducer arrays for nondestructive evaluation of thick metal sections and weldments, Review of Progress in Quantitative Nondestructive Evaluation 2A, 283-307 (1983).

A new type of electromagnetic-acoustic transducer has been developed that may be particularly suitable for use as an element of ultrasonic arrays. The new transducer can generate and receive compact ultrasonic pulses that exhibit a component of polarization parallel to the free surface. The advantages and inherent limitations of such systems are examined using analytical and numerical methods.

30. Fortunko, C. M.; Schramm, R. E. Evaluation of pipeline girth welds using low-frequency horizontally polarized waves, $J_{0}$ Nondestruct. Eval. 3, No. 3, 155-173 (Sept. 1982).

A new ultrasonic inspection method is described that permits complete volumetric inspection of the girth welds. The new system uses noncontacting electromagnetic-acoustic transducers that operate at low ultrasonic frequencies.

31. Fuller, E. R., Jr.; Fields, R. J.; Case, E. D.; Singhal, S. Nondestructive evaluation of distributed damage, NBS Reactor: Summary of Activities July 1981 through June 1982, NBS Technical Note 1178, 127-136 (June 1983).

During this first year, the research effort has focused on the detection and characterization of uniformly distributed microstructural damage through the use of the new small-angle neutron scattering (SANS) facility at NBS. Two model systems have been developed and utilized for these studies: (1) creep cavitation damage in 304 stainless steel and (2) uniformly distributed microcracks in a polycrystalline ceramic, yttrium chromite. 
32. Glinka, C. J. National Bureau of Standards small-angle neutron scattering spectrometer, Proc. Symp. on Neutron Scattering, Argonne, IL, 1981 (AIP Conf. Proc. 89), 395-397 (1982).

The instrument and its capabilities are discussed, along with measurements indicative of its performance.

33. Grot, R. A.; Chang, M. L. Thermographic inspection of exterior wall insulation retrofits, Thermal Insulation, Materials, and Systems for Energy Conservation in the 1980's, ASTM STP 789, 321-336 (1983).

A national demonstration of the effectiveness of an optimal weatherization program was conducted. Single-family dwellings were retrofitted and inspected with thermography equipment. The weatherization techniques included air infiltration reducing measures and modification or replacement of the heating systems. In order to assess the quality of the workmanship of the energy reducing measures applied to the building envelope, and in particular the quality of the installation of cavity wall insulation, thermographic surveys were performed after the completion of the weatherization work.

34. Grot, R. A.; Chang, Y. M.; Persily, A. K; Fang, J. B. Interim report on NBS thermal integrity diagnostic tests on eight GSA Federal office buildings. NBSIR 83-2768, 50 p. (September 1983). Available from NTIS as PB 84-104249.

This report summarizes preliminary results of diagnostic tests to evaluate the thermal integrity of eight office buildings. The test results include tracer gas measurements of air infiltration rates, pressurization tests of the air tightness of the building shell, and inspections of the envelope employing infrared thermography.

35. Harman, G. G. Acoustic-emission-monitored tests for TAB inner lead bond quality, Proc. 32nd Electronic Components Conf., 268-276 (IEEE, 1982).

This paper gives a brief introduction to acoustic-emission based tests applied to quality control in the electronics industry and describes some recent research on this testing technique. Acousticemission-monitored test systems to determine the inner lead bond quality for Tape Automated Bonding (TAB) have been developed. These include a pult tester and a microfatigue tester for off-line evaluation of bond quality and metallurgical system reliability as well as an automatic on-line production bond quality tester.

36. Hicho, G. E.; Eaton, E. E. Standard reference materials: A standard reference material containing 2.5 percent austenite (SRM 488). NBS Spec. Publ. 260-86, 23 p. (December 1983). SN003-003-02541-1.

This standard reference material is intended for the calibration of $x$-ray diffraction equipment used in determining the amount of retained austenite in hardened steels or, in very special cases, as an $x$-ray fluorescence standard for nickel content. 
37. Hicho, G. E.; Singhal, S.; Smith, L. C.; Fields, R. J. Effect of thermal processing variations on the mechanical properties and microstructure of a precipitation hardening HSLA steel, Paper 8306-051, Metals/Materials Technology Series, 9 p. (ASM, Metals Park, OH, 1983).

By varying the heat treatment of $A 710$, we have shown how the mechanical properties of this steel vary with particular changes in microstructure. Various microstructural studies indicated that the behavior observed here is entirely due to changes in precipitate size distribution. Small angle neutron scattering was found to be an effective means of studying how the precipitate distribution changes with heat treatment. It was also found that the total neutron cross section correlated very well with hardness.

38. Hocken, R. J.; Nanzetta, P. Research in automated manufacturing at the National Bureau of Standards, Proc. Tri-Service Workshop on Manufacturing Research, 31 May - 2 June 1983, Leesburg, VA, 8 p. (1983).

In late 1980, the National Bureau of Standards made a decision to develop and construct an automated manufacturing research facility to concentrate on machining and inspecting parts produced in small batches. The objective is support of research related to standards and processes for manufacturing and inspecting machined parts in small batches.

39. Hsu, N. N. Some thoughts on the ALN system, Report of the Committee on Physics Review of the Adaptive Learning Network Methodology, Report EPRI NP-3216, A61-A64 (Electric Power Research Institute, Palo Alto, CA, Oct. 1983).

40. Hubbard, C. R. New standard reference materials for $x$-ray powder diffraction, Adv. X-ray Anal. 26, 45-61 (1983).

Certification methods and results are presented for several new $x-r a y$ powder diffraction standard reference materials. SRM 640a silicon powder was certified for lattice parameter and is to be used as a $2 \theta$ calibration standard. SRM 675 fluorophlogopite was certified as a low $2 \theta$ standard to complement SRM $640 \mathrm{a}$. A set of five phases are being certified as intensity standards.

41. Hubbard, C. R. Certification of Si powder standard reference material SRM 640a, Jnl. of Applied Crystallography 16, 285-288 (1983).

A new lot of high purity silicon powder with mean crystallite size of about 2 micrometers has been certified as standard reference material 640a. This SRM can be used as both an external and an internal 2 theta calibration standard.

42. Hunston, D. L. Relationship between mechanical properties and performance of inks as the basis of quality control techniques, NBSIR 83-2691 (April 1983). 
43. Hunston, D. L. Cure monitoring of thermosetting polymers by an ultrasonic technique, Review of Progress in Quantitative Nondestructive Evaluation 2B, 1711-1792 (Plenum Publ. Corp., 1983).

An ultrasonic shear wave propagation technique has been developed that measures the dynamic shear properties of a thin film in a way which is both nondestructive and nonperturbing to any chemical reactions that may be occurring. The applicability of this test method was demonstrated with cure studies on two model systems; one based on tung oil, the other based on an epoxy resin.

44. Ichida, N.; Sato, T.; Linzer, M. Imaging the nonlinear ultrasonic parameter of a medium, Ultrasonic Imaging 5, No. 4, 295-299

(Oct. 1983).

45. Ives, L.; Swartzendruber, L.; Boettinger, W.; Rosen, M.; Ridder, S.; Blancaniello, F.; Reno, R.; Ballard, D.; Mehrabian, R.' NBS:

Processing/microstructure/property relationships in 2024 aluminum alloy plates, NBSIR 83-2669, 268 p. (April 1983). Available from NTIS as PB 83-207696.

The relationships between NDE measurements and important mechanical properties are affected by a large number of variables including: chemical composition, cast structure, ingot scalping, solution heat treatment and quenching, mechanical working, and aging treatment. A number of these relationships has been explored for 2024 aluminum alloy. A major result of our research has been a delineation of which alloy tempers and plate thicknesses are most likely to contain "soft spots" due to specific processing errors.

46. Jesch, R. L.; McLaughlin, R. H. Dielectric measurements of oil shale as functions of temperature and frequency, NBSIR 83-1683, 31 p. (January 1983).

A high-temperature sample holder designed by NBS was used to determine the dielectric properties of oil shale samples as functions of temperature and frequency. A description of the sample holder characterization is given along with the measurement procedure and the sample preparation.

47. Johnson, E. G. Simulating the scratch standards for optical surfaces - theory, Jnl. of Applied Optics 22, No. 24, 4056-4068 (Dec. 1983).

The author shows how to simulate the scattering generated by a scratch on the surface of high-quality optics and their elements. This is accomplished by first describing how the present cosmetic scratch standards tend to be used in the optics industry. Second, the author derives the first-order scattering coefficients for the far-field radiation due to a particular scratch pattern. The results allow construction of a set of secondary scratch standards. These are a pattern of rectangular grooves that can be made precisely reproducible during the manufacturing phase. Appropriate selection from this set can provide the same range of scattering power and character as is present in the current scratch standards, which are not easily reproducible. 
48. Kasen, M. B. Significance of blunt flaws in pipeline girth welds, Welding Research Supplement, Welding Journal 62, 117s-122s (May 1983).

The probability of crack initiation from porosity, slag, and arc burns in pipeline girth welds was investigated by subjecting highly-flawed welds to severe low-cycle, fully-reversed, strain-controlled fatigue. No effect of the flaw type or content was observed on the number of cyclic reversals to fatigue crack initiation. These results indicated that the probability of crack initiation from such flaws would be negligible under the essentially static loading to which pipelines are normally subjected.

49. Kasen, M. B.; Fortunko, C. M. Fitness-for-purpose criteria for pipeline girth welds, Proc. Pipeline Welding Inspection Conf.., Houston, Texas, September 21-22, 1982, 181-192 (Sept. 1982).

Results of a program to provide the basis for applying fracture mechanics principles to assessment of flaw significance in pipeline girth welds are reviewed. Subjects discussed are: (1) development of appropriate allowable flaw size curves, (2) development of an improved ultrasonic technique for sizing of sharp flaws, (3) the significance of blunt flaws, and (4) the demonstration of inherent limitations on the through-wall depths of blunt flaws.

50. Kasen, M. B.; Fortunko, C. M. Study of fitness-for-purpose criteria shows promise for pipeline girth-weld quality, Technology Oil Gas Inl., 83-93 (July 4, 1983).

See abstract for No. 49.

51. King, R. B.; Fortunko, C. M. Evaluation of residual states of stress and material texture using ultrasonic velocity measurements with electromagnetic acoustic transducers, Proceedings of 1982 Ultrasonics Symp., 885-888 (IEEE, 1982).

Procedures previously applied to the evaluation of stress with acoustic measurements are reviewed and it is shown that these involve using measurements with bulk waves propagating along the normal to the surface of a plate and do not provide sufficient information to separate the influences of stress and material property variations. To overcome this fundamental limitation, an alternative theory is developed that governs the propagation of shear waves polarized horizontally with respect to the surface of a plate, but propagating at oblique angles with respect to the surface normal. A practical procedure is developed that permits the evaluation of the in-plane components of the principal stresses in a plate exhibiting an unknown inhomogeneous initial anisotropy.

52. King, R. B.; Fortunko, C. M. Evaluation of residual stress states using horizontally polarized shear waves, Review of Progress in Quantitative Nondestructive Evaluation 2B, 1327-1338 (1983).

See abstract for No. 51 . 
53. King, R. B.; Fortunko, C. M. Determination of in-plane residual stress states in plates using horizontally polarized shear waves, Jnl. of Applied Physics 54, No. 6, 3027-3035 (June 1983).

See abstract for No. 51.

54. Knab, L. I.; Blessing, G. V.; Clifton, J. R. Laboratory evaluation of ultrasonics for crack detection in concrete, Am. Concr. Inst. J. 80, No. 1, 17-27 (Jan.-Feb. 1983).

A laboratory study was performed to quantify the capabilities of ultrasonic through-transmission methods to detect cracks in concrete. Pulse velocity and amplitude measurements were taken perpendicular to the crack plane (in cracked concrete) and compared with measurements parallel to the crack plane (in uncracked concrete). It was concluded that both velocity and amplitude were meaningful parameters in crack detection; however, velocity appeared to be more meaningful.

55. Larrabee, R. D.; Lowney, J. R. Measurement techniques for highresistivity detector-grade silicon: progress report, July 1, 1982 to June 30, 1983. NBSIR 83-2792 (December 1983).

Techniques for nondestructively characterizing the resistivity and excess-carrier recombination lifetime in ingots of high-resistivity, long lifetime detector-grade silicon are being evaluated. In particular, three interrelated techniques for nondestructively: (1) measuring an average resistivity, (2) profiling the low-level excess-carrier lifetime; and (3) profiling the resistivity of cylindrical ingot specimens are proposed and are evaluated. The conceptual and theoretical background for these measurements and the results of feasibility experiments obtained to date are presented.

56. Lawn, B. R. Indentation crack as a model surface flaw, Fracture Mechanics of Ceramics 5, 1-25 (1983).

Recent developments in sharp-indenter fracture techniques for the controlled study of strength-related properties of ceramics and glasses are reviewed. Major consideration is given to applications in two areas of strength analysis: flaw characterization and materials evaluation. For the first, surface-stress states associated with multiple-contact processes (e.g., machining), mirror fractography and flaw detection by acoustic wave scattering are topics in which residual-stress effects are manifest. For the second area, the use of indentation flaws for determining basic fracture parameters, such as toughness and crack-velocity exponent, is given special emphasis.

57. Ledbetter, H. M.; Kriz, R. D. Elastic-wave surfaces in solids, Status Solidi 114, 475-480 (1982).

Based on Christoffel-equation solutions, some interesting wavesurface topological features are described for anisotropic media. These features include crossovers of transverse-longitudinal surfaces and continuous transverse-longitudinal mode conversion over a single surface. Crossover of longitudinal and transverse surfaces means 
that a transverse wave velocity will exceed a longitudinal wave velocity. A longitudinal-transverse mode conversion means that both longitudinal and transverse modes exist on the same wave surface.

58. Linzer, M., ed. Ultrasonic Imaging 5, Nos. 1, 2, 3, 4 (Academic Press, New York, NY, Jan., April, July, Oct. 1983).

This journal provides for original papers concerned with the development and application of ultrasonic techniques, with emphasis on medical diagnosis. Papers deal with theoretical and experimental aspects of advanced methods and instrumentation for imaging, computerized tomography, Doppler measurements, signal processing, pattern recognition, microscopy, and measurements of ultrasonic parameters.

59. Linzer, M.; Norton, S. J. Current status of ultrasonic tissue characterization, Seminars in Ultrasound 4, No. 1, 3-9 (March 1983).

The questions that we address in this article are: (1) What are the prospects for measuring ultrasonic absorption and velocity in a clinical environment? (2) Can pulse echo images be made more quantitative? (3) What other tissue parameters are amenable to measurement?

60. Marx, E. Transient fields in dispersive media, Jnl. of Mathematical Physics 24, No. 11, 2602-2607 (1983).

The problem addressed in this paper is the determination of transmitted and scattered fields produced by a transient electromagnetic field incident on a three-dimensional body when the body and the surrounding medium are allowed to be dispersive. A simple conductor and a collisionless plasma are studied as examples.

61. Maxfield, B. W.; Fortunko, C. M. The design and use of electromagnetic acoustic wave transducers (EMATs), QualTest-2 Conference Proceedings, pp. 11-1 - 11-33 (ASNT, Columbus, OH, 1983).

The details needed to design SH wave and longitudinal and shear bulk wave EMATs using either permanent magnets or electromagnets to provide the bias field are explored. Additional considerations needed for high temperature, high speed, and other practical inspection situations are described.

62. Maxfield, B. W.; Fortunko, C. M. The design and use of electromagnetic acoustic wave transducers (EMATs), Materials Evaluation 41, No. 12, 1399-1408 (Nov. 1983).

The main objective of this paper is to describe how practical devices for different kinds of elastic wave generation may be constructed and used for making measurements. Several important aspects of the functioning of EMATs that are not part of the usual underlying theoretical description will be emphasized.

63. Maystre, D. Electromagnetic scattering from perfectly conducting rough surfaces in the resonance region, IEEE Transactions on Antennas and Propagation AP-31, No. 6, 885-895 (Nov. 1983). 
A rigorous integral formalism for the scattering from a cylindrical, perfectly conducting rough surface of arbitrary shape is introduced. The phenonemon of low range of the incident field permits the computation of the field scattered from a rough surface of arbitrary width.

64. McKnight, M. E.; Martin, J. W. Nondestructive corrosion detection under organic films using infrared thermography, Proceedings of the 14 th National SAMPE Tech. Conference, 349-358 (19 $\overline{82) . ~}$

A rapid, nondestructive testing procedure, using infrared thermography, has been developed for detecting corroded and blistered areas under pigmented organic coatings on metallic substrates. Software is being written to digitize the image and send the data to a computer for mathematical analysis, graphic display, and storage.

65. Mordfin, L. NDE Publications: 1981, NBSIR 83-2741, 42 p. (July 1983). Available from NTIS as PB 83-239574.

66. Mordfin, L.; Yolken, H. T. Nondestructive testing and quality improvement, Proceedings of $4 \mathrm{th}$ Pan Pacific Conference on Non-Destructive Testing, paper SAE-1, 8 p. (Australian Inst. for Non-Destructive Testing, Sydney, Australia, Nov. 1983).

Efforts to improve the quality of manufactured products and, at the same time, to achieve increased productivity, are nurturing changes in the role of nondestructive testing. It is evident that it is no longer adequate to use NDT merely to separate good parts from bad at the end of the manufacturing process. Instead, process controls are needed which will prevent the manufacture of defective products. A new role for NDT in the development of manufacturing process controls is proposed.

67. Muennemann, F.; Auld, B. A.; Fortunko, C. M.; Padget, S. A. Inversion of eddy current signals in a nonuniform probe field, Review of Progress in Quantitative Nondestructive Evaluation 2B, $1501-1526(1983)$.

The authors present a simple analytical method for predicting the eddy current signal produced by a-surface flaw of known dimensions, when interrogated by a probe with spatially varying magnetic field. Since inversion requires knowledge of the probe's magnetic field shape, the authors describe experimental methods which determine the interrogating field geometry for any eddy current probe.

68. Norton, S. J. Generation of separate density and compressibility images in tissue, Ultrasonic Imaging 5, 240-252 (1983).

The images can be obtained from near-field scattering measurements using only two long, rectangular transducer elements. This approach differs from conventional diffraction tomography in that no transducer arrays are required and broadband illumination is used. A flat transducer, assumed long relative to the extent of the object, is used as a source of broadband, plane-wave illumination, and as a 
receiver of the backscattered sound. A second transducer, oriented at a different angle with respect to the first, is used as a receiver only. The two transducers are rotated $180^{\circ}$ around the object, and the scattered sound is recorded at all angles during the rotation. This arrangement samples the plane-wave spectrum of the object directly and provides sufficient information to reconstruct independent images of the variations in both the density and compressibility of the scattering medium.

69. Norton, S. J.; Testardi, L. R.; Wadley, H. N. G. Reconstructing internal temperature distributions from ultrasonic time-of-flight tomography and dimensional resonance measurements, Proc. 1983 Ultrasonics Symposium, 850-855 (IEEE, Piscataway, NJ, 1983).

Two ultrasonic techniques for reconstructing the internal temperature distribution in metal bodies are described. An analysis of the tomographic reconstruction of temperature in a cylindrical body is presented together with initial experimental results. Dimensional resonance profiling is a new technique that allows the reconstruction of a one-dimensional distribution of temperature in a structure from measurements of its resonance frequencies. A combination of dimensional resonance and tomography is the best method for measuring temperature profiles in rectangular slabs.

70. Payne, B. F. The application of back-to-back accelerometers to precision vibration measurements, J. Research NBS 88, No. 3, 171-174 (May-June 1983).

Recent developments in improved calibration methods have given the back-to-back accelerometer a greater potential as an accurate, repeatable, and stable vibration standard. By adapting existing techniques of laser interferometric calibration to the special geometry of the back-to-back accelerometer, improved accuracy (over existing methods) can be obtained over the range of $2-15,000 \mathrm{~Hz}$ and extension to $20,000 \mathrm{~Hz}$ is a good possibility.

71. Persily, A. K.; Grot, R. A. Air infiltration and building tightness measurements in passive solar residences, Proc. 5th Annual Conf. ASME Solar Energy Division, 116-121 (ASME, New York, NY, 1983).

The measurements include pressurization tests to measure airtightness and tracer gas measurements to determine air infiltration rates.

72. Potzick, J. E.; Robertson, B. Long-wave acoustic flowmeter, ISA Transactions 22, No. 3, 9-15 (1983).

An acoustic flowmeter has been developed for measuring the flow of an arbitrary single-phase fluid in a pipe. Sound waves are induced in the fluid at two frequencies, one twice the other. The phases and amplitudes of the waves are detected by two microphones located in the wall of the pipe, one downstream from the other a distance of six diameters or more. The frequencies of the sound are automatically adjusted so that the shorter wavelength is equal to the distance 
between microphones. The instrument then measures in real time the volume flow rate of and the sound speed in the fluid, independent of fluid composition or temperature.

73. Prask, H. J.; Choi, C. S. Sub-surface residual stress measurements by means of neutron diffraction: aluminum, steel, and depleted uranium, Proc. 32nd Defense Conference on Nondestructive Testing, 62-69 (Materials Laboratory, Wright-Patterson AFB, OH, 1983).

Neutron diffraction has been used to nondestructively determine sub-surface residual stress distributions in aluminum, steel, and depleted uranium (DU) samples. The aluminum and steel were calibration samples with calculable stress distributions. For these, the expected stress distribution was obtained by the neutron diffraction technique. Two DU samples were studied: a furnace-cooled specimen, and a water-quenched, rotary straightened specimen. The neutron diffraction measurements showed the stress distributions in the two samples to be dramatically different. More specifically, the stress distribution in the rotary-straightened specimen was found to be asymmetric. The furnace-cooled sample was essentially stress free.

74. Proctor, T. M.; Breckenridge, F. R.; Pao, Y. H. Transient waves in an elastic plate: theory and experiment, J. Acoust. Soc. Am. 74 , No. 6, 1905-1907 ( $\mathrm{Dec} .1983$ ).

Waveforms calculated by generalized ray theory for a thick plate driven by a step-function point force are compared with experimental waveforms obtained on a glass plate using an improved piezoelectric displacement-sensing transducer.

75. Reed, R. P.; Kasen, M. B.; McHenry, H. I.; Fortunko, C. M. Fitnessfor-service criteria for pipeline girth weld quality. NBSIR 83-1695, 404 p. (Nov. 1983). Available from NTIS as PB 84-164448.

Criteria have been developed for applying fitness-for-service analyses to flaws in the girth welds of the Alaska Natural Gas Transmission system pipeline. A fracture mechanics model was developed and experimentally verified. Procedures for constructing flaw acceptance criteria curves are provided. A significantly improved ultrasonic method for detecting and dimensioning weld flaws was developed and demonstrated on pipeline sections. The probability of crack initiation from blunt flaws was shown to be very low. Suggestions are offered for field inspection procedures and for practical implementation of the criteria.

76. Reed, R. P.; Smith, J. H.; Christ, B. W. The economic effects of fracture in the United States. Part I - A synopsis of the

September 30, 1982, report to NBS by Battelle Columbus Laboratories. NBS Spec. Publ. 647-1, 19 p. March 1983. SN003-003-02470-8.

The study included all materials and all types of structures and included both fracture occurrence and fracture prevention costs. The study concluded that substantial material, transportation, and capital investment costs could be saved if technology transfer, combined with research and development, succeeded in reducing the factors of 
uncertainty related to structural reliability. Emphas is on fracture mechanics, inspection, and materials processing to achieve better structural reliability and material consistency, would result in equally safe or safer structures with less materials usage. Also see item No. 24.

77. Rosen, M.; Elkind, B.; Horowitz, E. Nondestructive characterization of microstructurally modified surface layers by means of Rayleigh waves, Report CMR-NDE-10 (Johns Hopkins University, Baltimore, MD, May 1983).

78. Rosen, M.; Friant, C. L.; Horowitz, E. Ultrasonic materials characterization of melt spun metallic ribbons, Report CMR-NDE-9 (Johns Hopkins University, Baltimore, MD, Feb. 1983).

79. Rosen, M.; Friant, C. L.; Nadeau, F.; Smith, J. J.; Horowitz, E. Ultrasonic nondestructive materials characterization of rapidly solidified microstructures, Report CMR-NDE-11, 83 p. (Johns Hopkins University, Baltimore, MD, Aug. 1983).

The research is discussed in the context of four tasks dealing with (1) determination of the elastic moduli of melt-spun metallic ribbons, (2) effect of composition on the crystallization kinetics and elastic properties of $\mathrm{Cu}-\mathrm{Zr}$ alloys, (3) nondestructive characterization of microstructurally modified surface layers by means of

Rayleigh waves, and (4) determination of phase stability criteria of extended solid solutions by nondestructive characterization.

80. Rosen, M.; Horowitz, E.; Wadley, H. N. G.; Mehrabian, R. Crystallization kinetics of amorphous alloys by ultrasonic measurements, Rapid Solidification Processing Principles and Technologies, III (Proc. 3rd Conference on Rapid Solidification Processing, Gaithersburg, MD, Dec. 1982), R. Mehrabian, ed., 416-423 (undated).

The crystallization kinetics were determined from ultrasonic wave propagation measurements, microhardness and optical metallography. Ultrasonic waves were generated using a laser pulse. The waves were piezoelectrically detected after propagation over a predetermined distance. It is conjectured that the frequency dependence of the ultrasonic attenuation, as interpreted within the framework of the theory of viscoelasticity, may explain the hardening process in the amorphous state.

81. Rosen, M.; Salton, Z. Temperature dependence of the sound velocity and ultrasonic attenuation in liquid $\mathrm{Bi}-\mathrm{Ga}$ and $\mathrm{Bi}-\mathrm{Sn}$ alloys, Materials Science and Engineering 58, 189-194 (1983).

The temperature dependence was determined by means of an ultrasonic pulse technique. The sound velocity is shown to be linear with temperature and parabolic with concentration. This behavior indicates correlation between the behavior of the electrical resistivity and of the sound velocity. Ultrasonic attenuation measurements permitted the accurate determination of the position of the interface (meniscus) between the separated liquid phases. 
82. Rowe, J. M. ; Glinka, C. J.; Berk, N.; LaRock, J.; Williams, R.; Fravel, D. Advanced neutron methods, NBS Reactor: Summary of Activities July 1981 through June 1982, NBS Technical Note 1178, 107-111 (June 1983).

The facility for small-angle neutron scattering (SANS) studies and the neutron time-of-flight (TOF) facility are described, together with a review of general instrument improvements at the NBS reactor.

83. Schaefer, R. J.; Rosen, M.; Smith, J. J.; Schechtman, D.; Mehrabian, R. Nondestructive characterization of Al-Mn alloys, Rapid Solidification Processing Principles and Technologies, III (Proc. 3rd Conf. on Rapid Solidification Processing, Gaithersburg, MD, Dec. 1982), R. Mehrabian, ed., 397-402 (undated).

84. Schrack, R. A. U-235 measurement by resonance neutron radiography, Final Report to U.S. Nuclear Regulatory Commission on FIN No. B8113, 57 p. (June 30, 1983).

85. Schrack, R. A. Book review, "Neutron Radiography - Proceedings of the 1st World Conference, edited by John P. Barton and Peter von der Hardt, D. Reidel Publishing Company, Dordrecht, Holland, Boston, and London, 1983; Price: \$126.00," Materials Evaluation 41, No. 13, 1476 (Dec. 1983).

86. Schrack, R. A.; Behrens, J. W.; Carlson, A. D. ; Bowman, C. D. ; Johnson, R. G. Recent developments in resonance neutron radiography, Proc. 5th Int. Conference Nondestructive Evaluation in the Nuclear Industry, 158-163 (ASM, Metals Park, OH, 1983).

An overview of developments in resonance neutron radiography at NBS is presented. The development of high-resolution, two-dimensional neutron detectors and their application in measurement systems using pulsed neutron sources is covered with special emphasis on the application to nuclear fuel materials analysis and evaluation.

87. Schrack, R. A.; Behrens, J. W.; Johnson, R. G.; Bowman, C. D. Resonance neutron radiography, Neutron Radiography (Proc. 1st World Conference on Neutron Radiography), 495-502 (D. Reidel Publ. Co., Dordrecht, Netherlands 1983).

The production of images by the use of neutrons having energies in the resonance region is described. Two-dimensional position-sensitive neutron detectors are used to produce transmission images using neutron time-of-flight techniques at the NBS electron linac facility. Two types of detectors are described. Resonance neutron radiography, using these detectors, has the capability of producing images with isotopic and chemical element discrimination in a complex matrix with a resolution of $1 \mathrm{~mm}$ or better.

88. Shorten, F. J., ed. NBS reactor: Summary of activities July 1981 through June 1982, NBS Technical Note 1178, 231 p. (June 1983) SN003-003-02493-7. 
The programs range from the use of neutron beams to study the structure of materials through nuclear physics and neutron standards to neutron radiography and nondestructive evaluation.

89. Smith, J. J.; Rosen, M. Nondestructive characterization of rapidly solidified Al-Mn alloys by ultrasonic and electrical methods, Report CMR-NDE-12 (Johns Hopkins University, Baltimore, MD, Nov. 1983).

90. Sternheim, M.; Van Gelder, W.; Hartman, A. W. A laser interferometer system to monitor dry etching of patterned silicon, J. Electrochem. Soc. 130, No. 3, 655-658 (March 1983).

A laser interferometer system to monitor plasma etch rate and to control etched depth of isolation areas in silicon for oxide isolated bipolar devices is reported. The etching process is stopped as soon as the desired etched depth is achieved. This method can be particularly useful in process development for observations in real time of changes in etch rate.

91. Tanimura, Y.; Teague, E. C.; Scire, F. E.; Young, R. D.; Vorburger, T. V. Graphical signatures for manufactured surfaces, Jnl. of Lubrication Technology 104, 533-537 (Oct. 1982).

Three dimensional surface signatures were calculated from radial profile measurements of two lapped specimens, two ground specimens and a milled specimen. These signatures are polar autocorrelation function ( $A C F$ ) maps and $R$ sub a maps. The ACF maps appear to be characteristic of the corresponding manufacturing methods. Therefore, radial profile measurement together with ACF maps is a useful technique for relating surface topographies to manufacturing processes.

92. Tschiegg, C. E.; Greenspan, M.; Eitzen, D. G. Ultrasonic continuouswave beam-power measurements; international intercomparison. J. Res. NBS 88, No. 2, 91-103 (Mar.-Apr. 1983).

Some quartz transducers designed and fabricated at NBS as transmitters of ultrasonic power appear to be sufficiently stable and linear to serve as standards. Therefore, an international intercomparison of measurements of continuous-wave power emitted by these standards was arranged. Each of the seven participating laboratories performed such measurements using one or more methods representing its practice.

93. Vorburger, T. V. FASTMENU: a set of FORTRAN programs for analyzing surface texture. NBSIR 83-2703, 123 p. (July 1983).

94. Whetstone, J. R.; Johnsen, E. G. Sensors for efficient energy utilization in the paper industry. NBSIR 83-2640, 45 p. (Feb. 1983). Available from NTIS as PB 83-164343.

A survey of the on-line process measurement needs of the paper industry has been completed. The results of the survey strongly indicate the need for new measurement technology. All of the processes are energy intensive and cannot be controlled either partially or completely due to the lack of measurement of specific process parameters. 
95. White, G. S.; Marchiando, J. F. Scattering from a V-shaped groove in the resonance domain, Applied Optics 22, No. 15, 2308-2312

(Aug. 1, 1983).

Radiation scattered from a $\mathrm{V}$-shaped groove in the resonance domain was measured and compared to predictions from a rigorous theory. The calculated scattering accurately predicted the number of peaks and general shape of the observed scattering. Small variations in groove shape were found to alter peak heights noticeably and peak positions slightly. Finite beam size caused unavoidable discrepancies between calculated and measured scattering.

96. Wu, W. L. Small-angle $x$-ray study of particulate reinforced composites, Polymer 23, 1907-1912 (Dec. 1982).

Small-angle $x$-ray scattering technique can be used to quantify the microvoids structure with in a particulate reinforced composite. An expression for the correlation function of three-phase systems has been derived in terms of the correlation function of the individual phases. By using this expression and the scattered intensities from the damaged and the undamaged composites, it has been shown that the volume fraction and the chord length of the microvoids can be obtained, provided no damage occurs to the reinforcement particles. In cases where the microvoids are preferentially oriented within the composites, an approximation scheme has also been developed.

97. Xu, Y.; Vest, C. M. Holographic téchnique for simultaneous measurement of displacement and tilt, Applied Optics 22, No. 14, 2137-2140 (July 15, 1983).

Real-time holographic interferometry performed with two very thin, parallel, closely spaced object illumination beams can be used to produce a time-varying irradiance which, when incident on a photodetector, gives a signal whose analysis indicates both the normal displacement and tilt at a point on the object surface. The signal also contains information about in-plane translation.

98. Yin, L. I.; Seltzer, S. M.; Bielefeld, M. J.; Trombka, J. I. Threedimensional imaging of $x-$ ray objects, Am. Nucl. Soc. Trans. 45, 256-257 (1983).

By means of computer-simulated results, the authors demonstrate the imaging of extended $x$-ray and gamma-ray-emitting objects using a non-overlapping redundant array (NORA). They explore the feasibility of using NORA for the imaging of weak $x-r a y$ and gamma-ray objects in both analog and digital modes.

99. Yin, L. I.; Trombka, J. I.; Ruitberg, A. P.; Seltzer, S. M. A small, battery-operated fluoroscopic system: Lixiscope with $x$-ray generator, Mater. Eval. 41, No. 7, 844-848 (June 1983).

A small, battery-operated $x$-ray generator has been developed to be used as part of a small-format fluoroscopic system, the Lixiscope (Low Intensity $X$-ray Imaging Scope). The complete fluoroscopic system is described, and some examples of possible applications are shown. 
100. Yin, L. I.; Trombka, J. I.; Seltzer, S. M.; Bielefeld, M. J. X-ray imaging of extended objects using nonoverlapping redundant array, Applied Optics 22, No. 14, 2155-2160 (July 15, 1983).

It is shown that with the nonoverlapping redundant array, the sidelobes no longer contribute to the background in the vicinity of a reconstructed image, and both signal and noise cross talks are completely eliminated. It may now be possible to reconstruct extended $x$-ray objects in 3-D by simple optical correlation and tomographically by a computer.

101. Young, M. Objective measurement and characterization of scratch standards, Proc. SPIE 362, 86-92 (1983).

The manufacture of scratch standards for use with MIL-0-13830A has been hampered by the lack of an objective measurement technique. NBS has therefore undertaken a program to provide quantitative measurements of the light scattered by the scratches and to correlate them with assessments made by trained observers. In this paper, the author describes a polar scanning apparatus, and shows scans from one set of secondary standards. Comparing these scans with the visual assessments is not straightforward.

102. Young, M. Can you describe optical surface quality with one or two numbers?, Proc. SPIE 406, 12-22 (1984).

This paper discusses total integrated scatter and the scratch and dig standard (MIL-0-13830A). Optics can measure only a bandwidth limited roughness. For this reason, the standard should perhaps be regarded as a scattered light standard and not as a surface roughness standard. I conclude by describing our use of a novel optical system to develop an objective measurement technique to aid in the manufacture of the artifacts used to implement the scratch standard.

103. Young, M. Linewidth measurement by high-pass filtering - a new look, Applied Optics 22, No. 13, 2022-2025 (July 1, 1983).

104. Youren, Xo; Vest, C. M.; Delp, E. J. Digital and optical moiré detection of flaws applied to holographic nondestructive testing, Optics Letters 8, No. 8, 452-454 (Aug. 1983).

Superposition of two double-exposure holographic interferograms creates moiré patterns that can be used to detect flaws. Relative magnification can be used to correct for imprecise replication of loading when the second interferogram is formed; it also can be used to detect flaws when only a single interferogram is used if the basic deformation field is radially symetric. 
Accelerometers, 70 .

Acoustic emission, $7,21,22,27,28,35,39,65,74$.

transducers, 15, 27, 28, 74 .

Acoustic velocity, 51-54, 56-59, 69, 72, 80, 81 .

Adaptive learning, 39.

Adhesives, 43.

Aerospace applications, 45, 99.

Aluminum and aluminum alloy, 3, 22, 45, 52, 53, 73, 83, 89 .

Amorphous alloy, 11,80 .

Art objects, 20.

ASTM, 12.

Austenite, 36.

Automated manufacturing (also see Robots), 38.

Autoradiography, 20.

Batch processing, 38 .

Bismuth alloy, 81 .

Bonding, 35.

Building technology, 18, 33, 34, 54, 71 .

Calibration, $7,8,12,15,26-28,36,70$.

Ceramics, 31, 56 .

Coatings, 64.

Composite materials, 3, 43, 96.

Concrete, 54.

Condition monitoring, 10.

Conductivity, electrical, 45, 55, 81.

Continuous monitoring, 27.

Copper and copper alloy, 11, 79, 80.

Corrosion, 64.

Cracks, 31, 48, 54, 56.

Creep, 31.

Cure monitoring, 43.

Dielectric measurements, 46 .

Dimensional resonance, 69.

Displacements, 97.

Distributed damage, 31.

Economics, 24, 76 .

Eddy current, $6,7,21,45,65,67$. probes, 67.

Elastic constants, $57,79,80$.

Electromagnetic acoustic transducer (EMAT), 29, 30, 51, 61, 62.

Electromagnetics, 89.

scattering, 60,63 .

Electronic applications, 35, 55, 90, 103.

Energy conservation, $18,33,34,46,71,94$.

Epoxy, 43 . 
Fatigue, 48, 75.

Film, organic, 64. photographic, 16.

Fitness for purpose, Fitness for service, 49, 50, 75.

Flaws, 48-50, 67, 104 .

Flow, fluid, 72 .

Fracture and fracture mechanics, $24,49,50,56,75,76$.

Gamma rays, 98.

Hardness (also see Microhardness), 37, 45, 80.

Heat treatment, 45.

Holography, 9, 97, 104.

Indentation testing (also see Hardness), 28, 56.

Infrared (also see Thermography), 25.

Ink, 42.

Interfaces, 81.

Interferometry, $70,90,97$.

Lasers, 55, 70, 80, 90 .

Leak testing, $6,21,33,34,65,71$.

Lenses, 47.

Light scattering (also see Electromagnetic scattering), 47, 95, 101.

Linewidth measurement, 103.

Liquid metal, 81.

Magnetic particle testing, 6,65 .

Magnetic tape, 16.

Manganese alloy, 83, 89.

Manufacturing processes, 66, 90, 91.

Materials processing, $37,45,76,80,83$.

Medical applications, 4, 58, 59, 68.

Microhardness, 11.

Microstructure (also see Texture), $37,45,77,79$.

Microvoids, 31, 96.

Moiré, 104.

\section{Neutron}

activation autoradiography, 20 .

cross section, 37 .

diffraction, $3,73,88$.

radiography (also see Resonance neutron radiography), 7, 85, 88.

resonance transmission analysis, 14.

scattering (see Neutron diffraction, Small-angle neutron scattering).

time of flight, 82, 87 .

tomography, 19 .

transmission measurements, 5 .

Nickel, 36.

Nuclear

fuel, 5, 14, 19, 21, 84, 86 .

reactor, $21,32,82,88$.

waste container, 19 . 
Oil shale, 46 .

Optical measurements (also see Holography, Interferometry), 7, 47, 55, 80, 103.

Palladium alloy, 11,80 .

Paper, 94.

Penetrant testing, 6,7 .

Pipelines, 30, 48-50, 75 .

Polymers, thermosetting, $16,43$.

Precipitation hardening, 37, 45.

Pressure vessels and piping, 21.

Probes (see Eddy current).

Process monitoring, 22, 35, 43, 66, 90, 94.

Productivity, 1,66 .

Quality control, 35, 42, 45, 66 .

Quartz, 40.

Radiography (also see X-ray, Neutron), 21, 65.

Rapid solidification, $22,80,83,89$.

Recording media, 16.

Residual stress (also see Stress analysis), 51-53, 73.

Resistivity (see Conductivity).

Resonance neutron radiography, $19,84,86,87$.

Resonance neutron tomography, 19.

Ribbon, metallic, 78,79 .

Robots, 1,2 .

Scratches, 47, 101.

Sensors, process, 1, 2, 66, 94 .

Silicon and silicon compounds, 3, 40, 41, 55, 90.

Sizing of discontinuities, $49,50,75$.

Small-angle neutron scattering (SANS), 31, 32, 37, 82 .

Small-angle $x$-ray scattering, 96.

Spectrophotometry, 17, 25, 26.

Standard reference material (SRM), 17, 36, 40, 41.

Standards, 7, 8, 12, 21, 26, 28, 47, 70, 92, 101, 102.

Stee $1,11,13,28,31,36,37,73$.

Stress analysis (also see Residual stress, Thermal stress), 3.

Surface roughness and texture, 13, 47, 63, 91, 93, 102.

Temperature measurement, 69.

Texture, microstructural, 51-53.

Thermal stress, 22.

Thermography, 18, 23, 33, 34, 64.

Tires, 9.

Tomography (see Neutron, Ultrasonic, X-ray).

Transducers (see Accelerometers, Acoustic emission, Eddy current, Ultrasonic).

Transmittance, 17, 25, 26.

Tribology, 10 . 


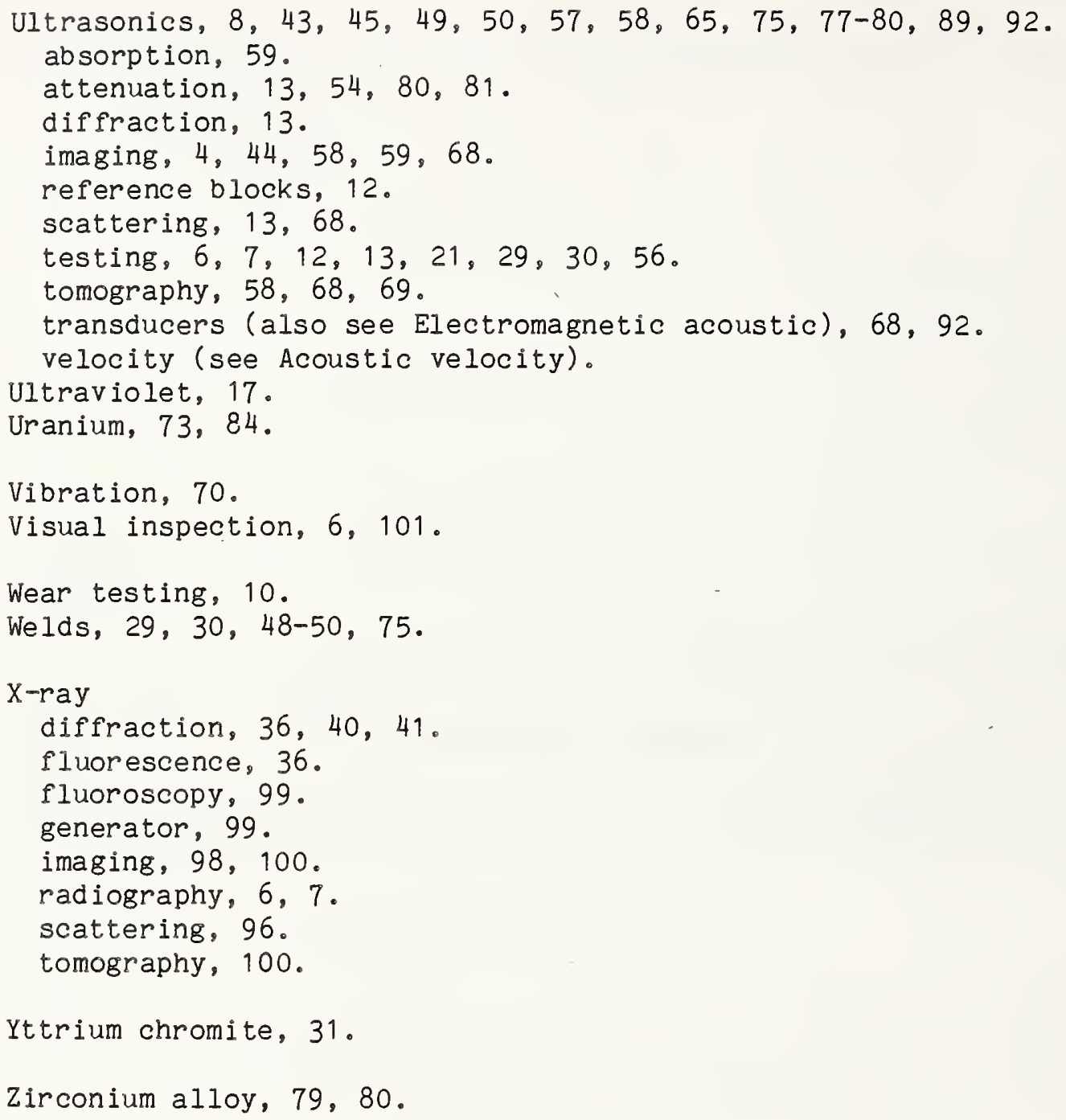


NBS Interagency Reports (NBSIRs) and NBS Grant/Contractor Reports (NBS-GCRs) may be purchased from the National Technical Information Service (NTIS), Springfield, VA 22161, telephone (703) 487-4560. NTIS accepts checks, money orders, VISA, Master Card, and American Express, or you may establish a deposit account. Your order must include the order number (e.g., the PB number) of each report desired. Order numbers and prices are available from the NBS Inquiry Service, E-07 Administration Building, National Bureau of Standards, Gaithersburg, Maryland 20899, telephone (301) 921-2318. Be sure to cite the NBS report number, the title, and the author of each publication in your inquiry.

Other NBS publications, such as Technical Notes (TNs) and Special Publications (SPs) are available from the Superintendent of Documents, U.S. Government Printing office (GPO), Washington, DC 20402, telephone (202) 783-3238. GPO accepts the payment methods enumerated above, except American Express. Your order must include the stock number (SN) for each publication requested; if you don't have it, contact the NBS Inquiry Service.

When GPO sells out, NTIS may have a few printed copies for sale. NTIS can also supply microfiche, or paper copy from microfiche, at any time.

Photoduplicated copies of many NBS publications may also be purchased from the Library of Congress. Write to the Photoduplication Service, Library of Congress, Washington, DC 20540, or call (202) 287-5640.

Some NBS publications are available at depository libraries for government publications. Your local library should be able to identify the nearest depository library.

Papers published in the Journal of Research or in non-NBS media are usually available from the authors, the publishers, or a technical library in your area.

For further information or assistance in obtaining copies, write to the Office of Nondestructive Evaluation, B344 Materials Building, National Bureau of Standards, Gaithersburg, Maryland 20899. 
NBS-114A (REV. $2 \cdot 8 \mathrm{C}$ )

U.S. DEPT. OF COMM

BIBLIOGRAPHIC DATA

SHEET (See in structions)

1. PUBLICATION OR

REPORT NO.

NBSIR $86-3396$

4. TITLE AND SUBTITLE

NDE Publications: 1983

5. AUTHOR(S)

Leonard Mordfin, editor

6. PERFORMING ORGANIZATION (If joint or other than NBS, see in structions)

7. Contrace/Grant No.

NATIONAL BUREAU OF STANDARDS

DEPARTMENT OF COMMERCE

WASHINGTON, D.C. 20234

8. Type of Report \& Period Coverec

Bibliography, CY 1983

9. SPONSORING ORGANIZATION NAME AND COMPLETE ADDRESS (Street, City, State, ZIP)

10. SUPPLEMENTARY NOTES

Document describes a compuser program; SF-185, FIPS Software Summary, is attached.

11. ABSTRACT (A 200-word or less factual summary of most significant information. If document includes a. significant bibliography or literature survey, mention it here)

This is the seventh is a series of bibliographies of NBS publications on nondestructive evaluation (NDE). It provides bibliographic citations, with selected abstracts, for 104 publications that appeared in the open literature, primarily during calendar year 1983. A detailed subject index is included as well as information on how copies of many of the publications may be obtained.

12. KEY WORDS (Six to twelve entries; alphabetical order: capitolize only proper names; and separate key words by semicolons) abstracts; acoustic emission; bibliography; eddy currents; leak testing; magnetic testing; neutron radiography; nondestructive evaluation; optical measurements; radiography; thermography; ultrasonics

13. AVAILABILITY

[X] Unlimited

For Official Distribution. Do Not Release to NTIS Order From Superintendent of Documents, U.S. Government Printing Office, Washington, D.C.
20402 .

14. NO. OF PRINTED PAGES

27

15. Price

$\$ 9.95$

X] Order From National Technical Information Service (NTIS), Springfield, VA. 2216I 
. 